\title{
Land fragmentation in southern Ontario: A tragedy of the spatial anticommons
}

\author{
Victoria Robson
}

\begin{abstract}
This study was conducted under the supervision of Jamie Baxter, Department of Food, Agriculture and Resource Economics; College of Management and Economics, University of Guelph
\end{abstract}

\begin{abstract}
Competition between agricultural operations, urban transplants, and ecological interests is changing the nature of property rights and land use in rural Ontario. In a region with valuable ecosystems and climate, soil, and location traditionally well-suited for crop and livestock production, plot sizes are decreasing as land is subdivided and allocated to non-agricultural residential use. Although this practice can increase property value for farmers, Michael Heller's spatial anticommons may also be observed, such that "each owner receives a core bundle of rights, but in too small a space for the most efficient use" [2]. The purpose of this paper is to introduce a new application of Heller's anticommons theory, examining how the increasingly patchwork-like distribution of rural land parcels can be expected to affect farm and ecosystem productivity. Ultimately, deadweight loss occurs because neither agricultural nor ecological economies of scale can be recognized on plots that are too small for efficient use. Using rural planning reports and habitat ecology studies, trends in the fragmentation process are described and compared to the aims of provincial land-use policy, including the Provincial Policy Statement, the Greenbelt Act, and the Places to Grow Act. While the goals of farmers and conservationists may at times seem discrete or incompatible, the anticommons framework may be used to identify shared challenges. Thus the two parties might consider how collective action could be used to overcome the difficulties of reuniting subdivided tracts of land.
\end{abstract}

$\mathrm{F}_{\mathrm{s} \text { o }}^{\mathrm{o}}$ or as long as humans have laid claim to resources, society has perceived the benefits of associating all of the responsibilities attached to an amenity with one individual. Modern property rights still reflect the basis of ancient Roman law: "nemo invitus ad communiuonmen compellitur", which states "no-one can be forced to have common property with another" [1]. Rights to private property, incorporating rights of use, division, and exclusion, are constructed and distributed to ensure that this maxim is fulfilled. In his paper, The Tragedy of the Anticommons: Property in the Transition from Marx to Markets, Heller introduces the theory of the anticommons, whereby resources are underused when multiple owners are endowed with the right to exclude other potential users [2]. Parallel to the anticommons is Heller's "spatial anticommons", in which an owner is unable to maximize the benefits of his core bundle of rights because a space is too small to implement them [2]. This paper argues that land fragmentation stemming from the right to property division has generated a spatial anticommons in rural Ontario, in which neither agricultural nor ecological economies of scale can be recognized because land plots are too small [3]. In addition, the provincial policies implemented to remedy land fragmentation are evaluated to determine efficacy in preventing and resolving the anticommons tragedy.

\section{HELLER's ThEORY OF THE ANTICOMMONS}

The concept of the anticommons was first explored by Michael Heller as a parallel to Hardin's familiar theory of the commons. Hardin argues that in a commons scenario, use rights are shared by a group of people, ultimately leading myopic, benefit-maximizing individuals to exploit a resource [4]. In an anticommons scenario, however, multiple owners are endowed with exclusion rights to a resource, such that no one has effective rights of use. Whereas Hardin's commons results in resource overuse, Heller's anticommons is prone to under use [2]. Suboptimal utilization and lost benefit occurs unless the multiple exclusion-rights holders can reach an agreement; this misallocation of scarce resources constitutes an economic loss as much as in the commons.

Furthermore, Heller specifically defines the "spatial anticommons": "each owner receives a core bundle of rights, but in too small a space for the most efficient use" [2]. In the spatial anticommons, deadweight loss is generated because units that would maximize value cannot be employed as a whole. The spatial anticommons has been identified by Hardin and Schluter in a variety of forms, including rental of rooms rather than a complete apartment, and harvest of small-scale private forests rather than large-scale forest tracts [2] [3]. In both cases, resources go idle, despite potential for 
increasing marginal benefits when the spatial scale is increased.

The tragedy of the spatial anticommons is directly related to the property rights regime that is applied to a resource. The prevailing understanding of property rights is one that defines the context of an individual's use of a limited resource [5]. In the case of land, this context includes the type of use, the division and boundaries of use, and the conditions under which these divisions can change.

A spatial anticommons in land exists when bundles of rights are applied to physical parcels that are too small to generate the maximum potential benefits that could occur if the parcels were combined. These benefits arise as a stream of returns from the use of land, such as residential development, agricultural output, or ecosystem health. Furthermore, land itself can have a variety of concrete characteristics. For each set of characteristics, there exists a land use with the greatest potential for benefits. In turn, each use requires a minimum parcel size upon which the benefit stream can be realized.

In a spatial anticommons, property rights either fail to select for a primary land use that best suits the qualities of the land itself, or subdivide the land into parcels that are too small for efficient application of the use. Buchanan and Yoon proffer that often, this occurs when the individuals creating and enforcing property rights policy do not have complete knowledge of a resource's potential for use, or lack personal interest in all possible uses of the resource over long periods of time. Because knowledge is incomplete, or the individual is not directly invested in maximizing rent from the land, the greatest potential gains are not captured [6]. Ultimately, there is nothing ingrained in a piece of land that prescribes what its property rights should be; instead, economists, landowners, and other stakeholders rely on policymakers to allocate land to the best use, in the most efficient parcel size [7].

\section{IDENTIFYing THE SPATIAL ANTICOMmons IN Agriculture}

In the modern agricultural economy, all of the spatial rights and responsibilities pertaining to a parcel of land are associated with a single owner. This rights structure makes it easier to sell, transfer, or subdivide land, which is necessary for new firms or individuals to acquire property. Parisi notes that while this process of subdivision and transfer is necessary for economic growth, it can also lead to spatial land fragmentation [1]. This occurs when land is divided into many non-conforming allotments, ignoring any complementary characteristics of the original parcel.

In the densely populated and rapidly expanding greater Golden Horseshoe of southern Ontario, land is a scarce resource with numerous competing end uses. The fastestgrowing metropolitan area in Canada, the regional population is expected to climb from 7.5 million people in 2009 to 11.5 million people in 2031 [8]. As population increases, so too does pressure on land. Pond describes how land that was at one time occupied predominantly by agriculture, sparse rural municipalities, and natural areas, is now in demand for nonagricultural residential development [8]. Between 1990 and 2000, for example, over 15000 new lots were created on agricultural land; 80 percent of these lots will be allocated for residential use. Of the new residential lots, Caldwell and Dodds-Weir report that half are possessed by rural, non-farm inhabitants [9]. Some such inhabitants are urbanites, who cite relocation to the countryside as an escape from "the ills of the city" [10]. For others, it is an opportunity to retire on a rural allotment without the responsibilities of a large tract of agricultural land. Nonetheless, each non-farm lot created in a traditional rural area fragments the agricultural land base [9].

Consequently, land fragmentation results in a checkerboard-like distribution of numerous small, isolated lots allocated to dissimilar land uses. However, land development is not the only pressure on farmland in southern Ontario. In addition, the arrangement and distribution of developed plots amid farm and conservation land tracts may alter agricultural and ecological systems' abilities to function efficiently. This paper argues that the small, segregated lots associated with land fragmentation frequently fall below the minimum area requirement for efficient agricultural or ecological use; therefore land fragmentation potentially presents a spatial anticommons.

Agricultural land is susceptible to the spatial anticommons tragedy because it is often allocated to uses that are not best suited to the land characteristics, or subdivided into parcels too small to maximize agricultural yield. In many instances, the two faults are correlated. Southern Ontario has 15.5 percent of Canada's Class One to Three farmland, and 56 percent of its Class One [8]. Land in the region is optimal for agriculture not only because of excellent soil quality, but also because the climate is wellsuited for a wide variety of crops [11]. However, intensified growth in the greater Golden Horseshoe creates a competitive dichotomy in which prime farmland is not allocated to its most efficient end use. Between 1976 and 1996, the total land lost to urbanization in Ontario was equal in area to the city of Toronto, and by 2001,12 percent of the province's most suitable farmland was allocated to urban development [8].

Land as a resource is tangible and inherently fixed; while its use may change, quantity will never increase. Unlike some economic inputs, such as labour, land is not entirely exchangeable between competing end uses. Undeveloped land, for example, retains development potential for aggregate extraction, housing, and industry. However once land has undergone development, its prime agricultural qualities are lost. While the competing use of agriculture does not exclude development, development excludes agriculture.

Furthermore, farmers and developers are myopic: the owners makes the profit-maximizing decision considering how long he can expect to receive profit from his land. This decision comes to the fore as a large demographic of Ontario 
farmers is rapidly reaching retirement [9]. In the greater Golden Horseshoe context, the property value of allotments outside of expanding urban centres is expected to rise as demand for residential and industrial land increases. This suggests that in many cases, farmers will choose to earn the greatest profit by selling or severing land for development use [12]. Although this act of sale and severance may seem innocuous, when the pattern of selling, dividing, subdividing and developing farmland parcels is compounded over time, the result is tracts of land that are no longer suitable in size for maximizing agricultural production.

Because agriculture is an intensive use of a nonrenewable, non-mobile resource, the size and geographical distribution of inputs inherently affects the efficiency of production [13]. Small parcels of farmland fail to maximize potential agricultural yield for reasons of economies of scale, economies of synergy, and increased transaction costs. Like all markets, agricultural markets are subject to change; Marsden et al. describe how modern agriculture has become more complex over time, relying less on small-scale production to satisfy increasing demand for high quality food at low prices [14]. Since 1951, the average size of an Ontario farm grew by 67 percent, while the number of farms decreased by 62 percent, illustrating the trend towards intensified, more specialized farming [8]. This trend towards larger farms emphasizes the importance of the economy of scale in agriculture, where average costs fall when fixed costs are spread over a larger number of hectares and additional returns are generated with each additional hectare acquired. Furthermore, a farm organized as a single large parcel rather than a series of fragmented smaller parcels facilitates the use and transport of equipment and people, application of fertilizer and pesticides, and installation of irrigation [15].

Fragmentation of farmland invalidates traditional economies of synergy, as described by Marsden et al., in which firms benefit from working in the same vicinity as other similar firms [14]. In agriculture, synergy manifests in farmers' capacity to network, form associations, and share knowledge. Moreover, economic synergy draws supporting capital, infrastructure, equipment purveyors, and markets to rural communities where little business incentive would otherwise exist. These communities derive branding benefits from association with quality of origins and traceability, which is reflected by increased value in the marketplace [14]. When a farming community is fragmented by nonagricultural residence and development, agricultural service providers are often pushed out of the market, and the benefits gained from linked farmland cannot be realized.

Finally, land fragmentation diminishes full benefits by increasing the transaction costs associated with expanding an agricultural operation. In an agricultural enterprise, the simplest way to increase profit is to increase production by acquiring more business units [14]. When the business unit (a plot of land) is small, more units must be acquired to achieve the same addition of area than if the units were larger. Thus when land is fragmented, farm owners must pay for more transactions to acquire the land needed to expand operations. When the plots of land are dispersed geographically and between owners, it can be impractical or impossible to acquire land that is for sale and contiguous with the existing farmstead [9].

This combination of impediments increases the number of transactions, the time spent negotiating, and the risk that reasonably-priced adjoining land plots do not exist. The most efficient use of farmland arises when economies of scale and synergy exist, and transaction costs are minimized. When farmland is fragmented, this does not occur; the small size and dissociated distribution of agricultural land parcels result in a lower stream of benefits than would exist if the parcels were reunited. Fundamentally, this inefficiency conjures a spatial anticommons tragedy.

\section{IDENTIFYING THE SPATIAL ANTICOMMONS IN ECOLOGY}

Although agriculture and residential development are perhaps the most commonly considered end uses for land in southern Ontario, land may also be conserved to protect the ecological integrity of an increasingly anthropogenic landscape. The land of southern Ontario exhibits value that is compatible with neither agriculture nor development in the form of biodiverse forest, watersheds, wetlands, and rare species' habitat. Ecological value, however, cannot be recognized if the plots of undisturbed land are distributed and divided within an isolating matrix of intensive land use [3]. Schluter informally dubs this concept the "ecological economy of scale" [3]. The Environmental Commissioner of Ontario reports that the rapid pace of rural land development that has created a patchwork arrangement of agricultural land has also fragmented ecosystems due to a general lack of understanding and concern for the natural environment [28].

Land fragmentation is manifested in the ecological context as land-use externalities and habitat fragmentation. Typical of a fragmented landscape, a large number of small, dispersed tracts present a greater total perimeter than a small number of larger tracts. It is along this perimeter, a margin where natural land meets farmland, that ecosystems are most susceptible to agricultural externalities. Weersink et al. argue that agricultural externalities are the greatest threats to rural ecosystems, and exists in a variety of forms, including soil erosion, fertilizer runoff, nutrient deposition, and groundwater contamination [16]. The commonality is that because harm occurs beyond the farmland boundary, damages are not assigned to the owner, and there is no incentive to desist. Externalities are imposed on society by means of increased water treatment costs and health risks [16]. The checkerboard of small parcels with differentiated uses creates an unnecessarily large interface between ecosystems and agricultural practices. By uniting small parcels with similar conservation use, the spatial anticommons caused by marginal agricultural pollution 
would be decreased and standard agricultural practice would no longer present a negative externality.

A second adverse environmental impact of land fragmentation, habitat fragmentation occurs when the arrangement of small tracts divides a large swathe of common biological community. Fahrig explains that a fragmented habitat is characterized by a series of smaller habitat plots, separated by a distinct matrix of habitat that is unlike the original [17]. For many species, survival declines as habitat becomes more restricted in size and isolated from similar patches [17]. Fleury and Brown add that this is particularly true of species that are low-density, migratory, or territorial [18]. Thus ecological spatial anticommons failure occurs specifically because breeding [19], predation [17], and foraging success [20] can only be realized on habitat patches larger than a minimum size. Furthermore, the failure of a single species population can trigger adverse implications for the entire trophic chain [17]. In absence of large habitat space, these flaws will compound: diverse internal structure will not form, the ecosystem will be unstable, and the risk of an ecosystem collapse will increase [18] [21] [22] [23]. Complete, long-term benefits derived from habitat conservation can only be realized when tracts of environmentally sensitive land are linked.

\section{The Provincial Policy Response to Land FRAGMENTATION}

Numerous policy responses have been implemented in a strategic approach to the developing inefficiencies in rural land occupancy and division. Such policies include the Provincial Policy Statement, Greenbelt Act, and Places to Grow Act. While these responses all assume an agricultural, rather than ecological, basis for response, the approaches are varied.

The Ontario Provincial Policy Statement (PPS), for instance, was issued under Section 3 of the Ontario Planning Act in a 2005 review, and attempts to apply policy-based planning to the changing nature of land use. In the rural context, the PPS balances conflict between existing agricultural and non-agricultural community members, and minimizing further urbanization of farmland. The first aspect of the PPS attempts to limit the negative impacts of traditional farming practices on non-agricultural rural individuals [24]. For example, the "minimum distance separation" requirement imposes a setback on livestock operations, such that the larger the enterprise, the further it must be from residential property [9]. Although the anticipation of conflict between neighbours is valid, the setback requirement is unpopular with farm owners; farmers claim that minimum distance requirements strictly limit the feasibility of expanding or establishing a livestock operation. Indeed, a study calculated that if each one-acre rural residential lot in Ontario restricts agricultural development within an 858 metre separation radius, over 7 million acres of land could be restricted from future use [11]. There are concerns that as agricultural parcels are subdivided and residential property encroaches on farmland, the problem will worsen [11].

In response, the PPS attempts to prevent residential subdivision, deny new residential lots on prime agricultural land, and remove the potential for farm owners to further subdivide farmland into small parcels or to allocate farmland to non-agricultural use [11]. This directly addresses land fragmentation by supporting a return to larger, unified farms [26]. However, reuniting fragmented farmland is not a focus.

The 2005 Greenbelt Act aims to protect farmland for agricultural production, and prevent urban encroachment towards natural areas [11]. Justification of the nonagricultural development moratorium is based upon the concept of Pigouvian externalities: a farming enterprise generates positive externalities in the rural community by supporting a market that would not otherwise exist. In Perth County, for example, every job on-farm creates 1.26 jobs offfarm, and every dollar input generates $\$ 1.52$ in total agricultural sales [26]. This multiplier effect supports numerous agriculture-related sectors, and the Greenbelt Act aims to protect the spillover of benefits that is generally not accounted for in planning.

While the spillover of benefits is a practical example of the economy of synergy that supports successful rural agricultural centres, some rural landowners argue that the Greenbelt Act prevents them from recognizing the true value of their property. But limiting development, the benefits of lot severance and development disappear and property value may decline.

Finally, the Places to Grow Act presents a regional growth-based approach to land use planning, embracing the unique contextual relationship between rural communities and local economies. Recommendations on the physical and social capital necessary for community growth are made based on where people, markets, and specialty land is expected to exist in the future [11]. The Act addresses land fragmentation and the spatial anticommons by emphasizing the benefit of harnessing economies of scale to create growth. This benefit can only be recognized when land is parceled and distributed efficiently by use.

\section{Overcoming The Spatial Anticommons}

Recommendations for managing the tragedy of the spatial anticommons in southern Ontario are twofold, and incorporate reuniting fragmented land parcels of common use and limiting prospective land fragmentation. The proposed reunification of fragmented land parcels is no easy task; indeed the tendency of property to divide rather than unite can be compared to the scientific law of entropy. Parisi explains that just as a gradient of energy pushes all closed systems towards disorder, landscapes fragment because the economic costs of dividing a parcel of land are less than the costs of reuniting the pieces [1]. When using policy to overcome this tendency, legislation must be very carefully 
critiqued before it is implemented; if land reunification procedure is redundant or burdens a landowner's time and budget, it will generate an entropic disincentive that keeps landowners from undertaking the initiative altogether. Furthermore, the characteristics of the land parcels should be compared to identify fragments that will be easiest to unite, and determine which will benefit the most from being reunited [1]. Ultimately, the goal is to maximize ex-post benefits, and reduce ex-ante financial and procedural transaction costs associated with re-establishing links between common-use land parcels.

While the aforementioned provincial policy responses to land development in rural Ontario attempt to prevent future farmland fragmentation, minimal focus is placed on the challenges of maintaining tracts of land with ecological value, or implementing solutions in a complex regulatory environment. In the case of agricultural externalities, owners of property characterized by watersheds or woodlands may instead seek out a solution based upon a common law framework to prevent the trespass of pollution at the property perimeter. In "ecology of scale" cases, the policy approach to habitat unification traditionally implements either habitat corridors or long-term ecosystem protection plans [27]. Both approaches, however, are case specific, and must be tailored to specific species, habitat types, and surrounding land use and ownership.

Furthermore, many farmers are concerned that existing policies ignore their interests as landowners. A fundamental criticism of existing policy is that when development and division potential of farmland is removed, the market value of farmland declines. It is troubling that this occurs at a time when agricultural household incomes are falling [14]. A survey of Ontario farmers by Caldwell and Dodds-Weir found that many consider it a right to perform a lot severance at some point in time, and in some cases, it is the only option for generating the profit necessary to sustain a farm [9]. Farmers plan to use income raised by selling or subdividing land to developers when structuring long-term financial arrangements. Therefore it is recommended that further policy resolve the problems associated with falling agricultural investment and equity before limiting a farmer's options for farmland use [9].

\section{CONCLUSION AND SUMMARY}

The system of property rights initially developed to prevent inefficient overuse of common land have resulted in a tragedy of inefficient underuse in southern Ontario. Land tends to fragment into plots that are too small to maximize either agricultural or ecological economies of scale. While a variety of provincial legislation exists to prevent farmland fragmentation, the policy's ability to balance short-term development and subdivision benefits with long-term environmental and agricultural value is mixed [12]. If a policy-based framework is to effectively re-establish the "black-hole" of benefit lost to inefficient division and distribution, it must consider the ecological, agricultural, and economic suitability of parcels for reunification.

With a final goal of maximizing long-term benefits derived from land, overcoming fragmentation will leave future generations with the land bases necessary for functioning agricultural and ecological systems. Effective policy must strike a balance between granting rural landowners the benefits associated with severing and selling land, and the value gained by keeping economies and ecologies of scale whole. Resolving the tragedy of the spatial anticommons by inhibiting fragmentation and reuniting plots will increase the agricultural and ecological scale benefits of rural land.

\section{REFERENCES}

1. Parisi, F. (2002) Entropy in Property. The American Journal of Comparative Law, 50:3, pp. 595-632

2. Heller, M. (1998) The Tragedy of the Anticommons: Property in the Transition from Marx to Markets. Harvard Law Review, 111, pp. 621-688

3. Schluter, A. (2008) Small-scale European forestry, an anticommons? International Journal of the Commons, $2: 2$, pp. $248-268$

4. Hardin, G. (1968) The Tragedy of the Commons. Science, 162:3859, pp. 1243-1248.

5. Coelho, M., J. Filipe \& M. Ferreira. (2009) Tragedies on Natural Resources: a Commons and Anticommons Approach. Technical University of Lisbon, Department of Economics Working Paper.

6. Buchanen, J.M. \& Y.J. Yoon. (2000) Symmetric Tragedies: Commons and Anticommons. Journal of Law and Economics, 43:1, pp. 1-13

7. Gibbs, C.J.N. \& D.W. Bromley. (1989) Institutional arrangements for management of rural resource property regimes. In F. Berkes (ed.) (1991) Common property resources: Ecology and community-based development. London: Belhaven Press.

8. Pond, D. (2009) Ontario's Greenbelt: Growth Management, Farmland Protection, and Regime Change in Southern Ontario. Canadian Public Policy, 35:4, pp. 413-432

9. Caldwell, W.J. \& C. Dodds-Weir. (2003) An assessment of the impact of rural non-farm development on the viability of Ontario's agricultural industry (Phase II Report). OMAFRA Rural Non-Farm Development Project.

10. Abelsohn, A., R. Bray, C. Vakil, \& D. Elliott. (2005) Report on Public Health and Urban Sprawl in Ontario. Environmental Health Committee, Ontario College of Family Physicians, pp. 53

11. Caldwell, W.J. \& W. Hilts. (2005) Farmland Preservation: Innovative approaches in Ontario. Soil and Water Conservation Society, 60:3, pp.66A-69A 
12. Russell, R. (2003) Equity in Eden: Can environmental protection and affordable housing comfortably co-exist in suburbia? Environmental Affairs, 30, pp. 437-487

13. Krugman, P. (1991) Increasing Returns and Economic Geography. The Journal of Political Economy, 99:3, pp. 483-499

14. Marsden, T., J. Banks, \& G. Bristow. (2002) The social management of rural nature: understanding agrarianbased rural development. Environment and Planning, 34, pp. 809-825

15. Ontario Ministry of Agriculture, Food \& Rural Affairs (2010) A Guide to Lot Creation in Prime Agricultural Areas. Government of Ontario. Retrieved from http://www.omafra.gov.on.ca/english/landuse/facts/lot draft.htm

16. Weersink, A., J. Livernois, J.F. Shogren, \& J.S. Shortle. (1998) Economic instruments and environmental policy in agriculture. Canadian Public Policy, 24:3, pp. 309327

17. Fahrig, L. (2003) Effects of Habitat Fragmentation on Biodiversity. Annual Review of Ecology, Evolution, and Systematics, 34, pp.487-515

18. Fleury, A.M. \& R.D. Brown. (1997) A framework for the design of wildlife conservation corridors specific application to southwestern Ontario. Landscape and Urban Planning, 37, pp. 163-186

19. Kurki, S., A. Nikula, P. Helle, \& H. Linden. (2000) Landscape fragmentation and forest composition effects on grouse breeding success in boreal forests. Ecology, 81, pp. $1985-1987$
20. Mahan, C. \& R. Yahner. (1999) Effects of forest fragmentation on behaviour patterns in the eastern chipmunk. Canadian Journal of Zoology, 77, pp. 19911997

21. Bowell, G.P., N.F. Britton, \& N.R. Franks. (1998) Habitat fragmentation, percolation theory, and the conservation of a keystone species. Proc. R. Soc. London, Ser. B, 265, pp. 1921-1925

22. Burkey, T.V. (1999) Extinction in fragmented habitats predicted from stochastic birth-death processes with density dependence. Journal of Theoretical Biology, 199, pp.395-406

23. With, K.A. \& A.W. King. (1999) Dispersal success on fractal landscapes: a consequence of lacunarity thresholds. Landscape Ecology, 14, pp. 73-82

24. Ontario Ministry of Municipal Affairs and Housing. (2005) Provincial Policy Statement. Toronto: Queen's Printer for Ontario.

25. Vyn, R. \& B. Deaton. (2008) The Effect of the Greenbelt on Farmland Property Values. Presentation to the Farm Level Policy Network, October 23, 2008.

26. Cummings, H. (2000) The Economic Impacts of Agriculture on the Economy of Perth County. Human Resources Development Canada/ Perth County Federation of Agriculture.

27. O’Hara, E.M. (2009) Moving from Landscape Connectivity Theory to Land Use Planning Practice: Ontario as a Case Study. University of Waterloo.

28. Environemental Commissioner of Ontario (ECO). (2000) Changing Perspectives: Annual Report 1999/2000. 